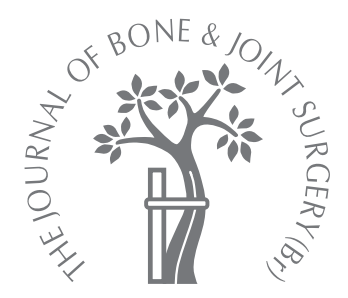

\title{
The use of a posterior lip augmentation device for a revision of recurrent dislocation after primary cemented Charnley/Charnley Elite total hip replacement
}

\author{
RESULTS AT A MEAN FOLLOW-UP OF SIX YEARS AND NINE MONTHS
}
J. McConway,
S. O'Brien,
E. Doran,
P. Archbold,
D. Beverland

From Musgrave Park Hospital, Belfast, Northern Ireland

\begin{abstract}
Between April 1992 and July 2005, 310 posterior lip augmentation devices were used for the treatment of recurrent dislocation of the hip in 307 patients who had received primary total hip replacements (THRs) using Charnley/Charnley Elite components with a cemented acetabulum. The mean number of dislocations before stabilisation with the device was five (1 to 16) with a mean time to this intervention from the first dislocation of 3.8 years $(0$ days to 22.5 years). The mean age of the patients at this reconstruction was 75.4 years (39 to 96 ).

A retrospective clinical and radiological review was carried out at mean follow-up of six years and nine months (4.4 months to 13 years and 7 months). Of the 307 patients, 53 had died at the time of the latest review, with a functioning THR and with the posterior lip augmentation device in situ. There were four revisions $(1.3 \%)$, one for pain, two for deep infection and one for loosening of the acetabular component. Radiolucent lines around the acetabular component increased in only six cases after insertion of the device which was successful in eliminating instability in $\mathbf{3 0 2}$ patients, with only five further dislocations $(1.6 \%)$ occurring after its insertion.
\end{abstract}

Recurrent instability after total hip replacement (THR) is a complex disabling problem and there are many reports detailing many causes and solutions. The posterior lip augumentation device (DePuy International Limited, Leeds, United Kingdom) was developed to address the problem of recurrent instability by constraining the femoral head within the acetabular component. ${ }^{1,2}$ The reported incidence of dislocation after THR ranges between $0.8 \%$ and $7 \% .{ }^{3}$ Numerous stabilising techniques have been described, including trochanteric advancement, ${ }^{4,5}$ revision of components, ${ }^{6-8}$ conversion to bipolar ${ }^{9}$ or tripolar arthroplasty ${ }^{10}$ and the exchange of a modular head-neck component and the polyethylene liner. ${ }^{11,12}$ However, none has had uniform success. ${ }^{2,13}$ Revision of components is often regarded as the best management but is technically demanding and not without complications. The posterior lip augmentation device was developed as an alternative to revision of otherwise stable components to restore stability to the hip, while minimising the surgical intervention. It consists of a piece of ultrahigh-molecular-weight polyethylene-bearing and a stainless-steel backing plate (Figs 1 and 2 ), both of which are predrilled to accept five self-tapping screws $4.5 \mathrm{~mm}$ in diameter and $25 \mathrm{~mm}$ in length. The inner curvature of the polyethylene bearing and the backing plate are also contoured to provide a congruent articulation with the head of the femoral component. The device is available for use with femoral heads of $22.225 \mathrm{~mm}, 26 \mathrm{~mm}$ and $28 \mathrm{~mm}$ in diameter.

Our aim was to evaluate retrospectively the clinical and radiological outcome associated with the use of a posterior lip augmentation device as a salvage treatment for instability and also to establish the complications associated with its use.

\section{Patients and Methods}

The device is secured on the posterior surface of the acetabular component so that it articulates against the head. A $3.2 \mathrm{~mm}$ diameter drill is then used which initially goes through the polyethylene of the acetabular component followed by the underlying cement and acetabular bone to a depth of at least $25 \mathrm{~mm}$ in order to accommodate the screws. When fixed in place, the femoral head is constrained within the augmented acetabular component (Fig. 3). The stability of the hip is confirmed by placing it through a full range of movement. If satisfac- 


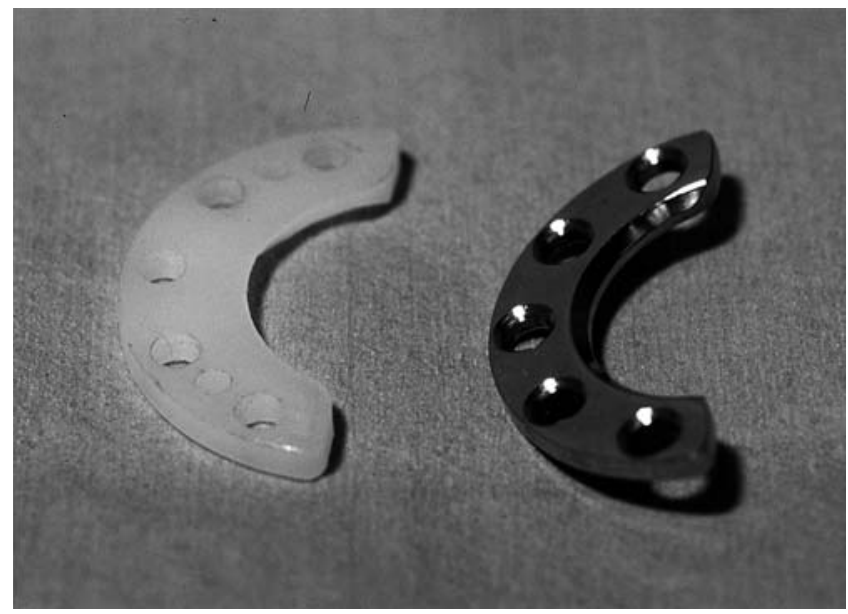

Fig. 1

Photograph of the augmentation device.

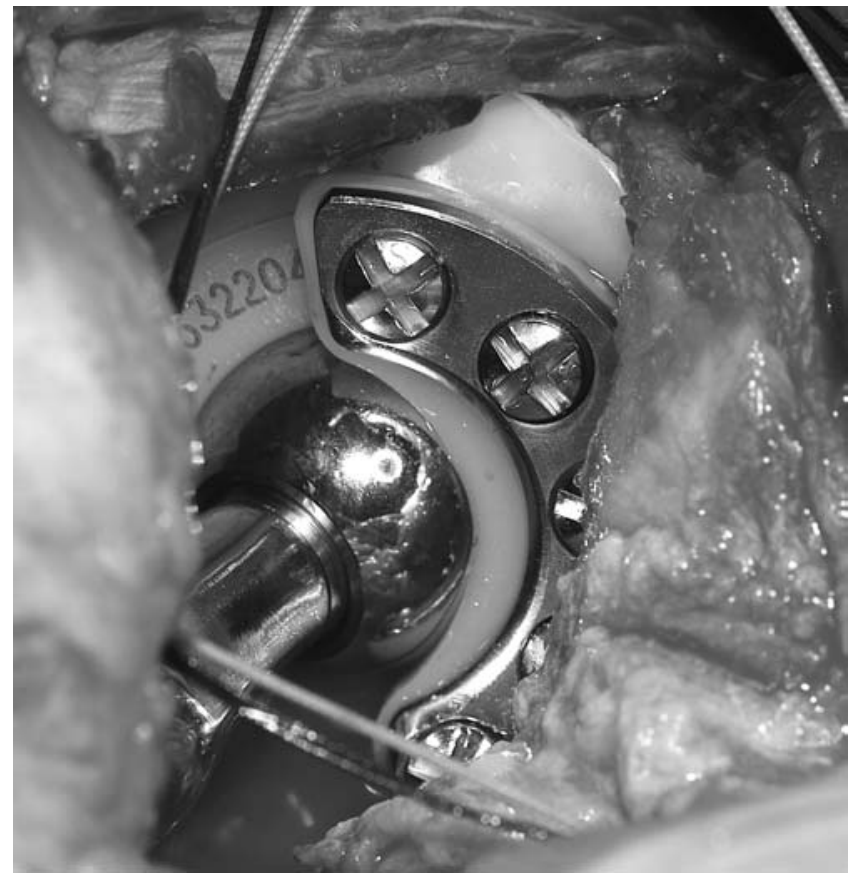

Fig. 2

Photograph of the augmentation device in situ in a left hip.

tory, mobilisation bearing full weight is commenced the following day with appropriate walking aids, but without immobilisation of the hip.

Between April 1992 and July 2005, we implanted 310 posterior lip augmentation devices into 307 patients (240 women and $67 \mathrm{men}$ ), as treatment for recurrent posterior dislocation (in all but one patient), of a primary THR. All had received a Charnley/Charnley Elite cemented acetabular component (DePuy International Limited). There were

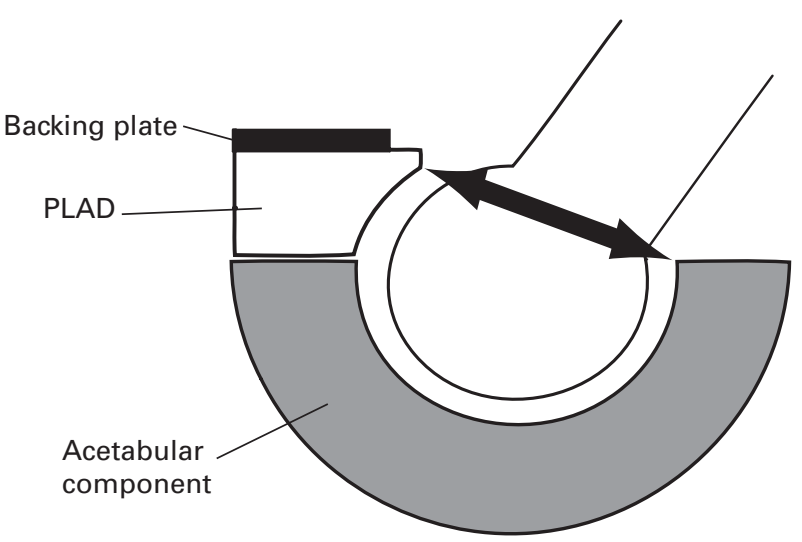

Fig. 3

Diagram showing the posterior lip augmentation device (PLAD) constraining the femoral head.

250 acetabular components with a $22.225 \mathrm{~mm}$ internal diameter and 60 with a $28 \mathrm{~mm}$ internal diameter.

The medical records and radiographs were reviewed. During the same time, 14489 THRs had been carried out, giving an insertion rate of $2.1 \%$.

The mean age of the patients was 75.4 years (39 to 96) at the time of insertion of the augmentation device. The mean age of the women was 76.2 years (37 to 96) and of the men 72.9 years (42 to 88 ). In total 182 procedures were performed on the right side and 128 on the left by 39 different surgeons doing a mean of eight each (1 to 60). The local research ethics committee gave approval for the study.

A posterior approach had been used for all the primary procedures. It has been suggested that this increases the risk of dislocation. ${ }^{14}$ The mean age at the primary THR was 70 years (37 to 96). Osteoarthritis (OA) was the underlying diagnosis in 281 hips $(90.6 \%)$ and the remainder were affected by a variety of conditions (Table I). The length of hospital stay after the primary THR was a mean of seven days (2 to 43 ).

After the first and second dislocations a closed reduction was performed and the patients were then mobilised and advice on precautions in hip positioning were reinforced before discharge. Our normal practice was to offer a posterior lip augmentation device only after the third dislocation. The direction of the dislocation was recorded as posterior in 309 hips and anterior in one.

The mean number of dislocations before implantation of the device was five (1 to 16), and the mean interval from the first dislocation to the device revision was 3.8 years $(0$ days to 22.5 years). In 286 hips $(92.3 \%$ ) three or more dislocations had occurred before the further operation. One case was unusual in that a device was implanted at the end of the primary operation. A total of $56(18 \%)$ implantations were performed within one year of the primary THR. 
Table I. Details of the primary diagnosis in the 310 hips

\begin{tabular}{lrll}
\hline Diagnosis & Number (\%) \\
\hline Primary osteoarthritis & 281 & $(90.65)$ \\
Avascular necrosis & 11 & $(3.55)$ \\
Developmental dysplasia & 2 & $(0.65)$ \\
Fractured neck of femur & 6 & $(1.93)$ \\
Perthe's disease & 3 & $(0.97)$ \\
Rheumatoid arthritis & 6 & $(1.93)$ \\
Slipped upper femoral epiphysis & 1 & $(0.32)$
\end{tabular}

Table II. Details of radiological complications (broken screws) in the 310 hips

\begin{tabular}{llc}
\hline Number of broken screws & Number of hips & Rate (\%) \\
\hline 1 & 18 (PLAD* stable) & 5.8 \\
2 & 3 (PLAD stable) & 0.97 \\
3 & 2 (PLAD stable) & 0.65 \\
4 & 2 (PLAD stable) & 0.65 \\
5 & 6 (PLAD migrated in 2 cases) & 1.93 \\
Total & 31 & 10
\end{tabular}

*PLAD, posterior lip augmentation device

At the time of review, 53 patients $(17.3 \%)$ had died. Their mean follow-up after insertion of the device was four years (6 days to 10 years and 10 months) and all died with a functioning THR and the device in situ. The remaining 254 patients $(82.7 \%)$ were subsequently reviewed. The mean duration of follow-up was six years and nine months (4.4 months to 13 years and 7 months) and 209 patients $(68 \%)$ had a follow-up of five years or more. A telephone review was carried out in 23 patients $(7.5 \%)$ because they were either too ill or unwilling to attend.

The records were examined and the patients consulted to identify the number of complications and dislocations after the procedure. The radiological outcome in terms of the formation of radiolucent lines, loosening of the socket, migration and revision of one or both components was also evaluated. The use of walking aids and the range of hip movement were assessed. All patients had clinical and radiological assessment at six weeks, six months and one and two years post-operatively. The latest review was carried out during 2005 and 2006. The Harris and Oxford hip score questionnaires ${ }^{15-18}$ were used to evaluate the functional outcome and were recorded at the final review.

\section{Results}

Intra-operative stability was considered to be improved in every hip. The mean length of hospital stay after the procedure was 12 days ( 2 to 124). The extended length of stay reflected the need for prolonged rehabilitation in this generally elderly group of patients. A total of 203 patients $(66 \%)$ were in hospital for ten days or less, contrasting with 19 $(6.2 \%)$ who were in hospital for one month or more. One patient aged 84 years was transferred to the hospital's elderly care unit and remained in hospital for a total of 124 days.

The range of movement after the insertion of an augmentation device expressed as a cumulative score of flexion, abduction, adduction and internal and external rotation was a mean of $188.7^{\circ}\left(100^{\circ}\right.$ to $\left.250^{\circ}\right)$. The mean Oxford hip score $(\mathrm{OHS})^{18}$ was 25 (16 to 40$)$ at the last review. The mean Harris hip score (HHS) ${ }^{16}$ was 75 points (43 to 96) at the latest follow-up. At a mean of six years and nine months after surgery, only five patients (1.6\%) (five hips) had a further dislocation. At the final review, of the total 307 patients, 221 (72\%) were mobile without any aids and $86(28 \%)$ were mobile with the use of various aids, of whom $16(5.2 \%)$ had ongoing pain around the hip. Only two patients remained immobile.

Complications. There were three deaths within 90 days. A further eight patients had died at the review at one year. No deep venous thrombosis was identified but three patients developed a non-fatal pulmonary embolism. Deep infection occurred in nine patients $(2.9 \%)$. Of these, five were treated with antibiotics, two by washout and antibiotics and two had a revision. Five patients $(1.6 \%)$ had a further dislocation. In four, there were no broken screws and in one all five screws were broken. There were two cases of palsy of the sciatic nerve with recovery in one. In the 16 patients with ongoing pain, trochanteric bursitis was considered to be the cause in 13 , four of whom had received an injection of steroid. Revision was performed in four patients $(1.3 \%)$ with three having a full revision. In one, revision was for pain (the cause of which was unclear), in two for deep infection as described above and in one for isolated loosening of the acetabular component. In this patient the acetabular component had been surrounded by a complete radiolucent line before insertion of the augmentation device and this increased afterwards.

At review, 31 augmentation devices $(10 \%)$ were found to have broken screws, in 18 of which only one was broken (Table II). In six patients, all five screws were broken and the augmentation device had become detached in two. Of the latter, in one the device had not migrated; in the other it had failed and migrated and two further dislocations had occurred. In one case the device itself had broken at the lowest screw hole, but without affecting the stability of the hip. This highly unusual situation has not recurred. Of five further dislocations, after insertion of the device only one had broken screws. This suggests that there is some correlation between breakage of screws and further dislocation although as the data show, there were four other cases in which all five screws were broken. To date they have not dislocated after insertion of the device.

Radiological examination identified evidence of socket demarcation in 185 hips (59.7\%), all of which showed this radiological feature before insertion of the device. An increase of the width of the radiolucent line after insertion of the device was seen in six hips (1.9\%). In two of these, revision was required (one for loosening and one for pain). In the remaining 179 , the radiolucent line did not increase. 


\section{Discussion}

Recurrent instability after THR is often multifactorial and is not associated with a clearly identifiable cause. Many risk factors have been proposed as contributing, such as wear of the polyethylene, the size of the head of the femoral component, malorientation of components, impingement, the surgical approach, age, gender, neuromuscular dysfunction, post-operative confusion and a history of alcohol abuse. ${ }^{19-23}$ In our series, most of the dislocations occurred in elderly women. ${ }^{14}$ Most of the femoral heads were small and had been implanted using a posterior approach. ${ }^{24,25}$ Revision arthroplasty for recurrent dislocation is associated with a high incidence of subsequent dislocation with rates ranging between $7 \%$ and $50 \%$. $7,26,27$

An alternative procedure is to augment the acetabulum with a device placed posteriorly. Our rate of dislocation after this procedure was $1.61 \%$. This is an improvement on the rates of dislocation currently quoted for revision after dislocation and compares well with rates quoted for primary surgery. 8,24

The posterior lip augmentation device differs from previous augments in that it is a bimodular device and the inner curvature of both components is machine-contoured (Fig. 1). The metal backing plate gives mechanical strength and stability while the contoured inner curve forms a congruent articulation with the femoral head. The main disadvantage of this device is that it is recommended for use only with Charnley/Charnley Elite cemented acetabular components and cannot be used to augment metal-backed cementless acetabular prostheses. Problems reported with acetabular augmentation include dislocation as a result of impingement of the neck on the added segment, ${ }^{28}$ breakage of screws $^{29,30}$ and, in one reported case, dislocation followed acetabular reconstruction with impaction grafting, resulting in the acetabular component being displaced because of the semicaptive state created by the device. ${ }^{29}$ Recurrent dislocation after the use of the device has been reported. ${ }^{29} \mathrm{We}$ feel that these complications can be minimised by correct placement of the device to minimise impingement of the femoral neck on the augment and by using five cortical screws to give a secure fixation. Originally, standard AO cortical screws were used, but screws with a low profile head were introduced in 1997 to minimise the chance of impingement. Despite careful placement, one or more screws were broken in 31 hips $(10 \%)$ in our series, suggesting some impingement, with the possibility of increasing stress on the acetabular component and the potential for accelerating its wear.

Previous studies have found that the insertion of a posterior lip augmentation device, compared with a revision THR, is associated with a reduced operating time, lower intra-operative blood loss, reduced requirements for transfusion, a shorter time spent in high-dependency care and a reduction in the overall length of the hospital stay. ${ }^{1,2}$ Others have found that this device gives satisfactory control of recurrent dislocation, but have stressed the need to ensure that fixation of the acetabular component is sound before insertion of the device. ${ }^{29}$ We have been successful in achieving the main goal of preventing further instability of the hip with $302(98.4 \%$ ) patients (305 hips) having no further dislocation at a mean follow-up of six years and nine months and with only five subsequent dislocations. Despite the success in the restoration of stability, the use of any constrained device is associated with concerns related to the decreased range of movement, the potential for impingement and increased stresses which may predispose these hips to increased risks of wear, osteolysis and loosening. Nevertheless, we have found few increases in radiolucent lines around the acetabular component which suggested that there was no substantial link between insertion of the device and loosening. Our experience of using it to obtain stability has been successful and we continue to recommend its use, but we recognise that gross malposition and excessive wear of polyethylene of the acetabular component are relative contraindications.

No benefits in any form have been received or will be received from a commercial party related directly or indirectly to the subject of this article.

\section{References}

1. Charlwood P, Thompson NW, Brown JG, Nixon JR. The Belfast Posterior Lip Augmentation Device (PLAD) in the management of recurrent posterior dislocation following primary total hip arthroplasty. J Bone Joint Surg [Br] 2001;84-B(Suppl II): 154.

2. Charlwood AP, Thompson NW, Thompson NS, Beverland DE, Nixon JR. Recurrent hip arthroplasty dislocation: good outcome after cup augmentation in 20 patients followed for 2 years. Acta Orthop Scand 2002;73:502-5

3. Yuan LJ, Shih CH. Dislocation after total hip arthroplasty. Arch Orthop Trauma Surg 1999;119:263-6.

4. Ekelund A. Trochanteric osteotomy for recurrent dislocation of total hip arthroplasty. J Arthroplasty 1993;8:629-32.

5. Kaplan SJ, Thomas WH, Poss R. Trochanteric advancement for recurrent dislocation after total hip arthroplasty. J Arthroplasty 1987;2:119-24.

6. Daly PJ, Morrey BF. Operative correction of an unstable total hip arthroplasty. J Bone Joint Surg [Am] 1992;74-A:1334-43.

7. Fraser GA, Wroblewski BM. Revision of the Charnley low friction arthroplasty for recurrent or irreducible dislocation. J Bone Joint Surg [Br] 1981;63-B:552-5.

8. Wroblewski BM, Siney PD, Fleming PA. The angle-bore acetabular component and dislocation after revision of a failed total hip replacement. J Bone Joint Surg [Br] 2006;88-B:184-7.

9. Ries MD, Wiedel JD. Bipolar hip arthroplasty for recurrent dislocation after total hip arthroplasty: a report of three cases. Clin Orthop 1992;278:121-7.

10. Grigoris P, Grecula MJ, Amstutz HC. Tripolar hip replacement for recurrent prosthetic dislocation. Clin Orthop 1994;30:148-55.

11. Lachiewicz PF, Soileau E, Ellis J. Modular revision for recurrent dislocation of primary or revision total hip arthroplasty. J Arthroplasty 2004;19:424-9.

12. Toomey SD, Hopper RH Jr, McAuley JP, Engh CA. Modular component exchange for treatment of recurrent dislocation of a total hip replacemnet in selected patients. J Bone Joint Surg [Am] 2001;83-A:1529-33.

13. Goetz DD, Capello WN, Callaghan JJ, Brown TD, Johnston RC. Salvage of a recurrently dislocating total hip prosthesis with use of a constrained acetabular component: a retrospective analysis of fifty-six cases. J Bone Joint Surg [Am] 1998;80A:502-9

14. Morrey BF. Difficult complications after hip joint replacement. Clin Orthop 1997;344:179-87.

15. Dawson J, Fitzpatrick R, Murray D, Carr A. The problems of 'noise' in monitoring patient-based outcomes: generic, disease specific and site-specific instruments for total hip replacement. J Health Serv Res Policy 1996;1:224-31.

16. Fitzpatrick R, Morris R, Hajat S, et al. The value of short and simple measures to assess outcomes for patients of total hip replacement surgery. Qual Health Care 2000;9:146-50. 
17. Harris WH. Traumatic arthritis of the hip after dislocation and acetabular fractures: treatment by mold arthroplasty: an end-result study using a new method of result evaluation. J Bone Joint Surg [Am] 1969;51-A:737-55.

18. Dawson J, Fitzpatrick R, Carr A, Murray, D. Questionnaire on perception of patients about total hip replacement. J Bone Joint Surg [Br] 1996;78-B:185-90.

19. Hedlundh U, Karlsson M, Ringsberg K, Besjakov J, Fredin H. Muscular and neurologic function in patients with recurrent dislocation after total hip arthroplasty. J Arthroplasty 1999;14:319-25

20. Nicholl JE, Koka SR, Bintcliffe IW, Addison AK. Acetabular augmentation for the treatment of unstable total hip arthroplasties. Ann R Coll Surg Engl 1999;81:127-32.

21. Paterno SA, Lachiewicz PF, Kelley SS. The influence of patient-related factors and the position of the acetabular component on the rate of dislocation after total hip replacement. J Bone Joint Surg [Am] 1997;79-A:1202-10.

22. Turner RS. Post-operative total hip prosthetic femoral head dislocations: incidence, aetiologic factors and management. Clin Orthop 1994;301:196-204.

23. Woolson ST, Rahimtoola ZA. Risk factors for dislocation during the first three months after primary total hip replacement. J Arthroplasty 1999;14:662-8.
24. Bourne RB, Mehin R. The dislocating hip: what to do, what to do. J Arthroplasty 2004;19(4 Suppl 1):111-14.

25. Berry DJ, von Knoch M, Schleck CD, Harmsen WS. Effect of femoral head diameter and operative approach on risk of dislocation after primary total hip arthroplasty. J Bone Joint Surg [Am] 2005;87-A:2456-63.

26. Woo RY, Morrey BF. Dislocations after total hip arthroplasty. J Bone Joint Surg [Am] 1982;64-A:1295-306.

27. Güngör T, Hallin G. Cup re-enforcement for recurrent dislocation after hip replacement. J Bone Joint Surg [Br] 1990;72-B:525.

28. Gie GA, Scott TD, Ling RS. Cup augmentation for recurrent hip replacement dislocation. J Bone Joint Surg [Br] 1989;71-B:338.

29. Campbell D, Muthusamy K, Sturdee S, Finlayson D, Stone M. The posterior lip augmentation device for recurrent dislocation. J Bone Joint Surg [Br]2001;84-B/Suppl II): 154

30. Williamson JB, Galasko CSB, Rowley DI. Failure of acetabular augmentation for recurrent dislocation after hip arthroplasty: report of 3 cases. Acta Orthop Scand 1989;60:676-7. 